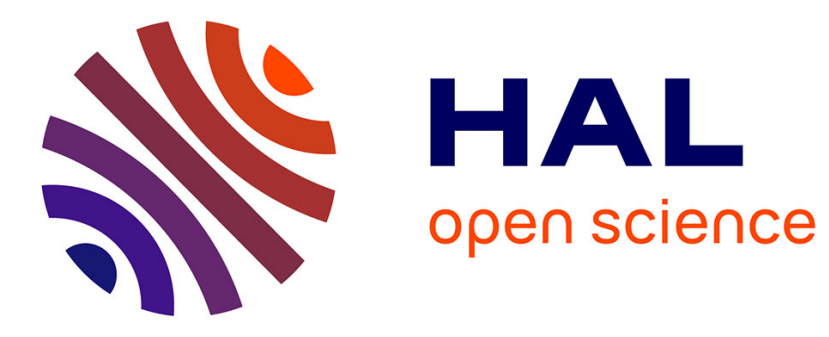

\title{
Thermomechanical analysis of an aircraft tire in cornering using coupled ale and lagrangian formulations
}

\author{
Ange Kongo-Kondé, Iulian Rosu, Frédéric Lebon, Olivier Brardo, Bernard
}

Devésa

\section{- To cite this version:}

Ange Kongo-Kondé, Iulian Rosu, Frédéric Lebon, Olivier Brardo, Bernard Devésa. Thermomechanical analysis of an aircraft tire in cornering using coupled ale and lagrangian formulations. Central European Journal of Engineering, 2013, 3 (2), pp.191-205. 10.2478/s13531-012-0049-6 . hal-00833555

\section{HAL Id: hal-00833555 \\ https://hal.science/hal-00833555}

Submitted on 7 Mar 2018

HAL is a multi-disciplinary open access archive for the deposit and dissemination of scientific research documents, whether they are published or not. The documents may come from teaching and research institutions in France or abroad, or from public or private research centers.
L'archive ouverte pluridisciplinaire HAL, est destinée au dépôt et à la diffusion de documents scientifiques de niveau recherche, publiés ou non, émanant des établissements d'enseignement et de recherche français ou étrangers, des laboratoires publics ou privés. 


\title{
Thermomechanical analysis of an aircraft tire in cornering using coupled ale and lagrangian formulations
}

\author{
Ange Kongo Kondé ${ }^{1,2}$, Iulian Rosu², Frédéric Lebon ${ }^{2 *}$, Olivier Brardo ${ }^{1}$, Bernard Devésa ${ }^{1}$ \\ 1 Airbus Operations, 316 route de Bayonne, 31060 Toulouse cedex 03, France \\ 2 LMA CNRS UPR 7051, Aix-Marseille University, Centrale Marseille, 31 chemin Joseph-Aiguier, 13402 Marseille cedex 20, France
}

\begin{abstract}
The thermomechanical behavior of an aircraft tire is predicted, using experimental devices, a model based on finite element software and an appropriate method of expressing the heat generated by skid in terms of the local friction coefficient, depending on the temperature. In the thermomechanical model, a steady state mechanical analysis is combined with a transient thermal problem. This combined approach is based on three main computing steps: the deformation step, the dissipation step and the thermal step. The deformation step calculates the stress and the velocity fields, which are used as inputs in the dissipation step to calculate the heat generated due to friction. The internal dissipation is assumed to be negligible. Finally, the thermal step yields new thermal maps based on the heat flux computed in the dissipation step. The coupling is established by updating the friction coefficient in the first two steps.
\end{abstract}

Keywords: Finite element $•$ Steady state rolling $•$ Temperature $•$ Thermomechanical analysis

\section{Introduction}

Many factors can affect the safety of an aircraft during its lifetime and thus expose the aircraft and its passengers to risks. The landing and take-off operations are the most critical phases: the high speed, the sometimes violent impact of landing gear during the touch-down phase, fast braking, ground irregularities, poor weather conditions (wind, snow, etc.) and other parameters can make the steerage perilous. Information about the contact forces at the tire/ground interface makes it possible to understand and master the

*E-mail: lebon@lma.cnrs-mrs.fr behavior of the tires and provides aircraft designers and airlines companies with flight mechanics models giving ground reaction data which can be used throughout the development phases and during the operations of aircraft. Experimental data obtained on real tires, at low and moderate speeds, are used here to draw up a data base. However, some physical limitations (such as the power of engines, the tarmac run length, etc.), the large non-linearities occurring in these applications make it difficult to reach high speeds in these models and to extrapolate from the results obtained. The large non-linearities are due mainly to the components of pneumatic tires, and their geometry, since they undergo large transformations and to the loading conditions (inflated pressure, vertical load), as well as to some 


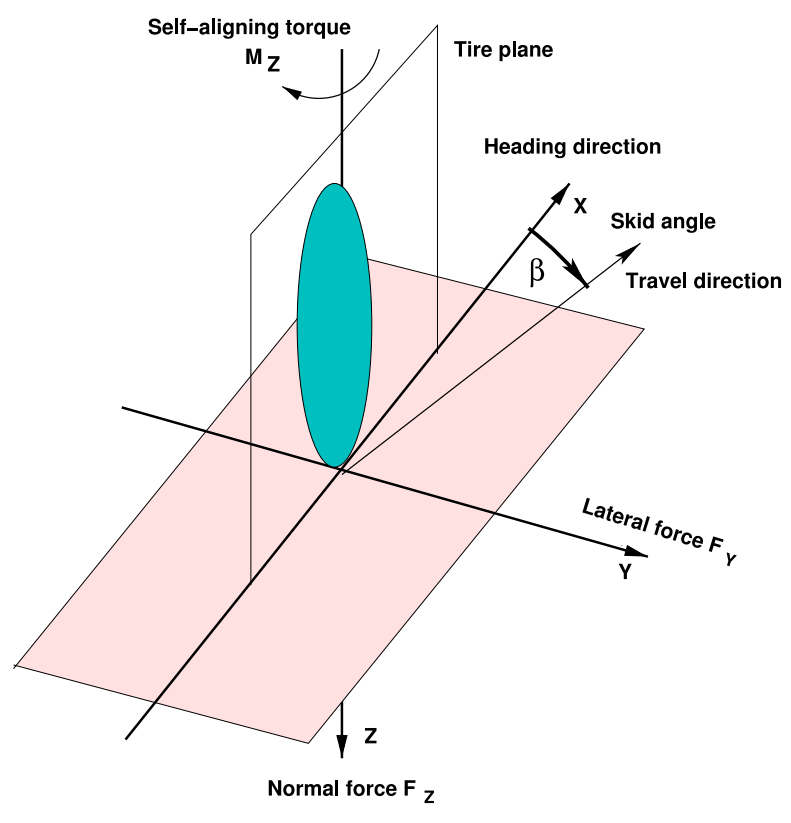

Figure 1. $F_{Y}$ and $M_{Z}$ definitions [39].

coupled phenomena (contact, friction, thermomechanical coupling, wear, etc.).

In vehicle simulation studies, tires are among the most challenging components, since they have to support the weight of the vehicle, cushion the vehicle against surface irregularities, provide sufficient traction for driving and braking, and provide steering control and direction stability. In the context of vehicle dynamics, tire models can be used to predict tire rolling behavior in terms of parameters such as the Lateral Friction Coefficient (L.F.C) $\mu_{Y}$ and the Self Aligning Torque (S.A.T) $M_{z}$ generated by the interactions between the tire and the road surface (Figure 2). These parameters quantities define respectively the tire grip (tire/ground) potential and the ability of a tire to regain the steering direction when the driver releases the controls. The lateral friction coefficient is the quotient of $F_{Y}$ and $F_{Z}$. The lateral force $\left(F_{Y}\right)$ is the resultant of the forces produced by a non-zero camber angle and by a non-zero slip angle during cornering. $F_{Z}$ is the vertical load.

The self-aligning torque $\left(M_{z}\right)$ produces a restoring moment on the tire to realign the direction of travel with the direction of heading when the slip angle is non-zero [39] (see Figure 1).

The existence of a critical sideslip angle $\beta_{\max }$ value has been observed experimentally at which $\mu_{Y}$ decreases (Figure 2) and $M_{z}$ quickly tends towards null and sometimes negative values. This finding has been attributed to thermal effects occurring in the contact patch due to friction [1]. This characteristic $\beta_{\max }$ value depends on loading parameters such as the vertical load, the weight of vehicle,

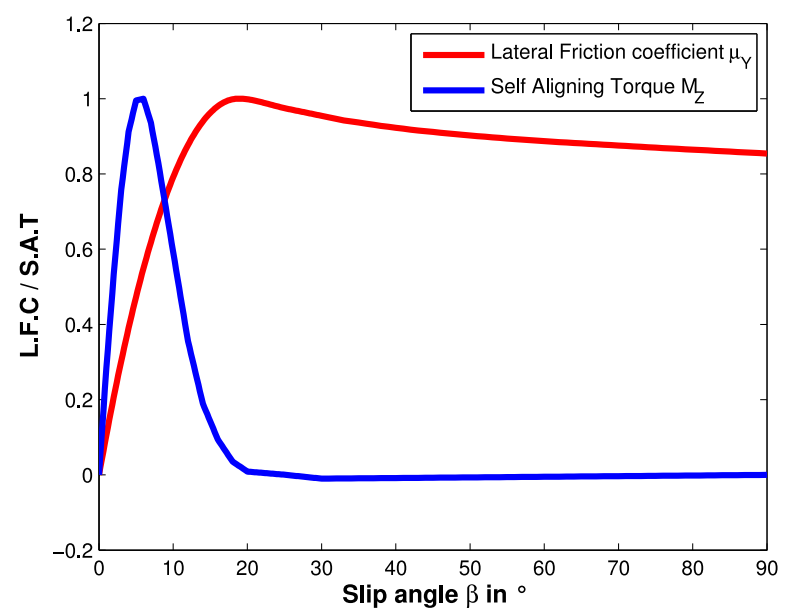

Figure 2. $\mu_{Y}$ and $M_{z}$ in the case of an aircraft tire. $\beta$ denotes the slip angle. The specific values have been normalized.

the ground velocity, etc. $[2-5,39,40]$. It, therefore, seemed to be necessary to develop a tire model in which these thermomechanical effects were taken into account.

However, determining the thermomechanical behavior of vehicle tires in general, and of aircraft tires in particular, is a highly complex task requiring much hard work due to the kind of problem to be solved, i.e., a non-linear dynamic thermo-viscoelastic coupling problem with heat sources resulting both from internal (due to the viscoelasticity) volumetric sources and superficial (due to the friction) sources in a very complex structure requiring detailed knowledge of the geometry, the properties of the materials, the friction coefficient, the dissipative mechanisms, the thermal coefficients and other parameters. Several experimental $[6,7]$ and numerical [8-14] attempts have been made on these lines, and the authors have used various simplified models and methods to reduce the complexity of the analysis, depending on the accuracy required, the nature of the problem under investigation, the type of tire involved, the experimental conditions and the computational resources available.

A simplified approach to the thermomechanical analysis of a tire is presented here, where the mechanical model previously described in [4] is extended to include the thermal effects. In this approach, a steady state mechanical problem is expressed in terms of steady state transport capability and coupled to a transient thermal (convection/diffusion) problem using temperature-dependent friction coefficient. This dependency is proved by means of a very basic device inspired by Coulomb's friction test rig. This approach is original because of the way the stationary problem is coupled to a transient one in the tire cornering simulation context and the way frictional dissipation is introduced into the thermomechanical analysis. 


\section{Theoretical foundations of rolling tire simulations}

Finite Element Analysis (FEA) of rolling tires has generally been carried out using three different numerical algorithms. In the first method, the implicit time integration approach is used and the time effect is thus directly incorporated into the finite element model equations $[4,47]$. The second method is the "Steady State Transport" method, whereby ALE-formulation is used to compute the steady state response of rotating tires $[15,16]$. The third approach is based on use of the explicit time integration method of simulating the dynamic behavior of a rolling tire under transient conditions. This model can be used to model the real time behavior of a rolling tire under normal operating conditions [17-19]. In cornering simulations, the second technique can be used to compute the total tire response in a single simulation, which is not possible with the other 2 methods. The Steady State rolling based on an ALEformulation has therefore been used in studies of this kind to overcome the disadvantages of both implicit and explicit transient methods. The primary objective of using ALE mesh motion is to reduce the total number of elements by employing fine and coarse elements in different regions and maintaining their respective location with respect to the material deformation and the contact conditions. This enables significantly smaller models. The basics of the ALE method could be found in [42-46].

\subsection{The steady state transport method}

The great advantage of the Steady State Transport Method is that it involves the use of a moving reference frame in which rigid body rotation is described in Eulerian terms and the deformation is described in Lagrangian terms. Theoretical foundations and explanations are given in [20]. The kinematic description converts the steady moving contact problem into a pure spatially dependent simulation. The effects of friction, inertia and the history of the material can all be accounted for. The computation of the deformed tire shape and of the contact area for given loading pessure, tire velocity and skidding angle are based on this method. For further details, see [20].

\subsection{Thermal model}

During contact with friction between two bodies $\left(\Omega_{1}\right.$ and $\Omega_{2}$ ), heat is generated in the contact zone due to the dissipated energy.

In a general frame, solving a thermal problem leads to finding the solution of the heat equation (1) with Dirichlet and

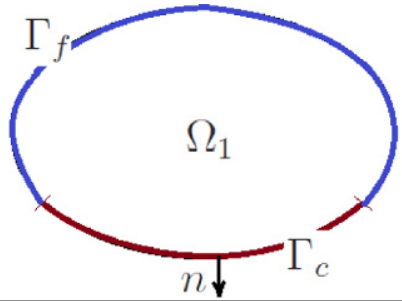

$\Omega_{2}$

Figure 3. Two bodies in contact.

Neumann boundary conditions (convectivity, adiabacity and given temperature).

$$
\rho c_{p} \frac{d T}{d t}=\operatorname{div}(k \cdot \nabla T)+Q
$$

where $\rho$ is the mass density $\left(\mathrm{kg} / \mathrm{m}^{3}\right), c_{p}$ is the specific heat $\left(J k g^{-1} K^{-1}\right), k$ is the thermal conductivity $\left(W m^{-1} K^{-1}\right), T$ is the temperature $\left({ }^{\circ} K\right), Q$ are the internal heat sources $\left(W^{-3}\right)$ and $t$ is the time $(s)$. The internal heat sources correspond to mechanically generated internal energy sources. In the following this source $Q$ will be neglected. This hypothesis will be justified in Sections 5 and 6 .

The boundary $\Gamma_{1}$ of $\Omega_{1}$ is divided in two parts: $\Gamma_{c}$ and $\Gamma_{f}$, where $\Gamma_{c}$ is the contact boundary between $\Omega_{1}$ and $\Omega_{2}$, and $\Gamma_{f}=\Gamma_{1}-\Gamma_{c}$. On $\Gamma_{c}$, the heat flux source $q_{c}=k \cdot \nabla T . n$ is caused by friction:

$$
q_{c}=\eta \lambda_{T} \cdot \dot{u}_{T}
$$

where $\eta$ is the heat flux sharing coefficient between the tire and the ground, $\lambda_{T}$ is the tangential stress in the contact and $\dot{u}_{T}$ is the tangential speed in the contact. In the numerical applications presented in the present paper, $\eta$ will be assumed to be equal to 0.9 . This heat sharing coefficient, with values between 0 and 1 , gives the ammount of heat flux generated by friction that goes to the tire and to the road. For $\eta=0.9,90 \%$ of heat flux goes to the tire and $10 \%(1-\eta)$ goes to the ground.

On the free boundary $\Gamma_{f}$, the heat flux is caused by surface convection heat exchange between the tire and the air and is given by:

$$
\alpha\left(T-T_{\text {ext }}\right)+k \cdot \nabla T . n=0
$$

where $T_{\text {ext }}$ is the farfield air temperature and $\alpha$ is the coefficient of heat transfer (thermal convection coefficient) which is different for each zone: the inflating surface $S_{1}$, sidewall $S_{2}$ and the tire/rim zone $S_{3}$ (see Figure 4). The numerical values are presented in Table 4 . Note that the initial temperature $\left(T_{0}\right)$ is set equal to $20^{\circ} \mathrm{C}$. 


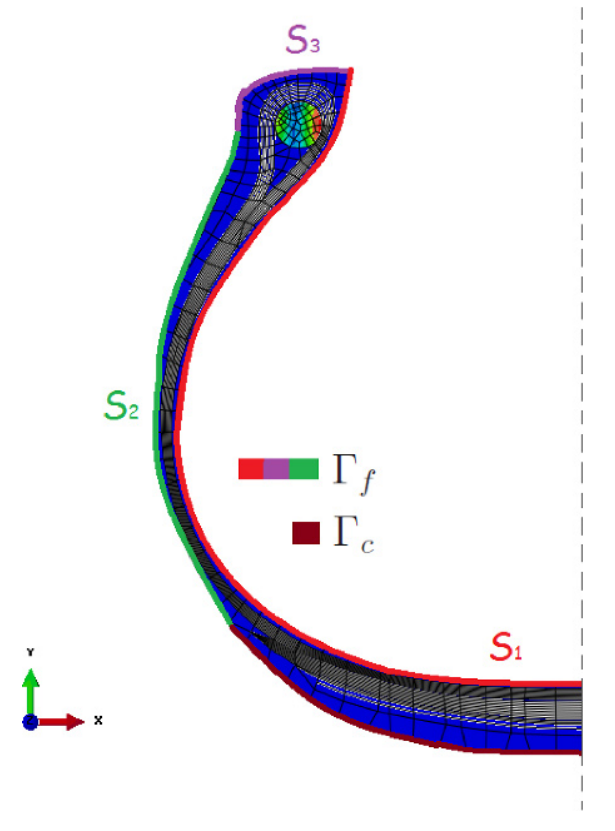

Figure 4. Thermal boundary conditions.

\section{Finite element model for tire ana- lysis}

\subsection{Constraints to be considered}

Modern tires consist of a specific combination of rubber compounds, cord and steel belts [22]. The main parts of a these tires are their body, sidewalls, beads, and tread (see Figure 5). The body is made of rubberized fabric layers, called plies, that give the tires strength and flexibility. The fabric is made of rayon, aramid, nylon, or polyester cords. Covering the plies are sidewalls and tire tread of chemically treated rubber. The sidewalls form the outer walls of the tire. Steel loops, called beads, holding the tire to the rim are embedded in the two inner edges of the tire. The rubber components have different characteristics, depending on their functional purpose. The tire tread, for example, comes into direct contact with the ground and has to be much harder than the sidewalls.

\subsection{Finite Element Model (FEM)}

The aim of the present study is to predict the cornering behavior of an aircraft tire in contact with a flat rigid surface. The tire is subjected to an inflation pressure $p_{0}$, a concentrated load on the axle $F_{Z}$ and a rolling velocity $v_{0}$. The geometry of the three-dimensional tire presented in Figure 5 can be modeled with or without any grooves. The Mooney-Rivlin model is used to characterize the behavior

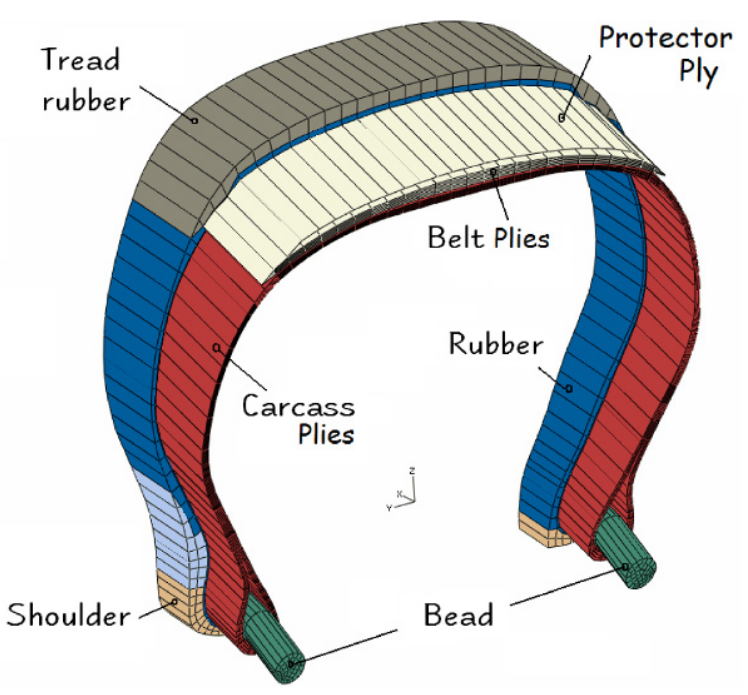

Figure 5. Finite Element Model and tire structure model.

of the rubber parts and an elastic model with Young's modulus $E$ and Poisson's ratio $v$ is used for the reinforcing zones (plies, belt, etc). The material properties were based on experimental tests (tension, compression tests, etc.) on samples cut from the various parts of the tire. The rim is considered as a rigid body. The tire/rim contact is simplified by assuming that tire adheres to the rim. All the nodes at the tire/rim interface are therefore connected to the reference rim node and the rim is assumed to be rigid.

\subsection{Tire geometry}

Since no data concerning the tire cross-section geometry or the inner plies and materials were available from the manufacturers, we have cut the tire using a water jet as shown in the figure below (Figure 6). This method gives the 2-D section of the tire including all its inner features: we can therefore clearly distinguish all the composite layers and count exactly the number of reinforced fibers embedded into the rubber and measure their dimensions, as shown in Figure 6.

\subsection{Constitutive model for tire materials}

Since rubber is highly extensible, and large strains are observed experimentally [23, 24], small-strain elasticity theory using moduli $E$ and $G$ (the shear modulus) is not suitable for describing the response of tires to large strains, whereas the mechanical energy $W$ stored in a unit volume as the result of the deformation provides a useful means of measuring these responses.

In tire applications, rubber compounds are often assumed to be isotropic, and cord/rubber composites are assumed to be 

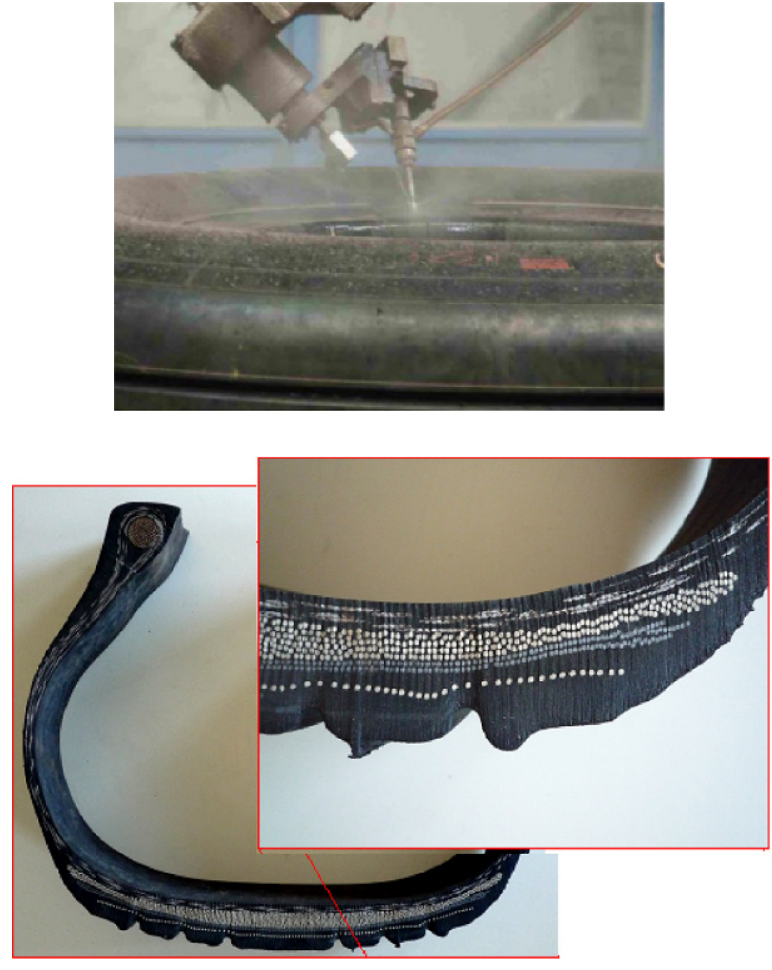

Figure 6. Water jet cutting and layout of the composite structure.

elastic. These elements combined together can withstand the severe structural and thermal operating conditions encountered. In this section, it is proposed to briefly describe the hyperelastic models and linear elastic properties used to define the mechanical characteristics of the rubber and the belt and ply layers.

\subsubsection{Hyperelastic constitutive model for rubber}

There are a number of models which have been used to describe the non-linear relation of stress-strain in rubbers, of which the most important models are Arruda-Boyce [25], Ogden et al. [26], Polynomial (Neo-Hookean, Yeoh, Mooney-Rivlin,..) [27], Van der Waals [28].

In tire modeling studies, the incompressible Mooney-Rivlin model is commonly used [16, 29-32]. Thus, the material constants $C_{10}(\mathrm{MPa})$ and $C_{01}(\mathrm{MPa})$ will be define from the strain energy function $W$ expressed as the Mooney-Rivlin form:

$$
W=C_{10}\left(\bar{l}_{1}-3\right)+C_{01}\left(\bar{I}_{2}-3\right)+\frac{1}{D}\left(J_{e}-1\right)^{2}
$$

where $W$ is the strain energy potential (or strain energy density), $\bar{l}_{1,2}$ stands for the first two deviatoric strain invariants, $J_{e}$ is the elastic volume ratio and $D$ introduces compressibility [36]. We set $D$ equal to infinity for fully

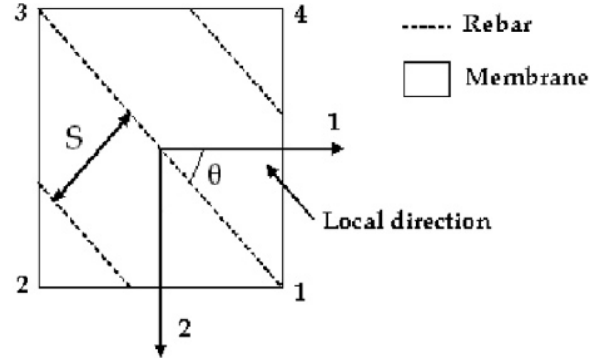

Figure 7. Rebar defined in terms of the local coordinate system.

incompressible materials. Based on the test data, the material properties of each rubber can be determined by curve fitting $[5,33]$ as it is shown in Figure 8.

\subsubsection{Mechanical behavior of cord/rubber composite materials}

Composite materials consist of at least two different constituents or components that are bonded together. The two materials are generally used to obtain a structure, meeting specific thermomechanical requirements. The most commonly used composite materials in structural applications are those in which either continuous or chopped fibers are embedded in a softer matrix.

In the present study, the reinforcement was modeled using a Rebar approach [36], which treats the reinforcement as a one-dimensional component. This means that the cordrubber composites, such as the belt, carcass, and bead reinforcements, are modeled in the form of rubber reinforced by Rebar elements, (see Figure 7). The properties of the Rebar element depend on the elastic modulus, which is determined by performing simple tension tests.

The properties of the Rebar components differ from those of the underlying components, and their orientation can be defined relative to the local coordinate system as shown in Figure 7. To define the Rebar reinforcement, one must specify the cross sectional area $A$ of each Rebar component, the spacing $S$ between two consecutive cords, and the orientation angle $\theta$ of Rebar cord in the local frame [41].

\subsubsection{Experimental determination of rubber and rein- forcement properties}

There are two possible ways of determining the material properties to be analyzed. They can either be by testing rubber and cord-rubber composites, or calculated from the measured properties of the composite's constituents. The load-displacement responses of cord/rubber composites are generally non-linear and hysteretic, and engineering judgement is therefore used to determine the best hyperelastic model, depending on the strain obtained on the basis of experimental data. 


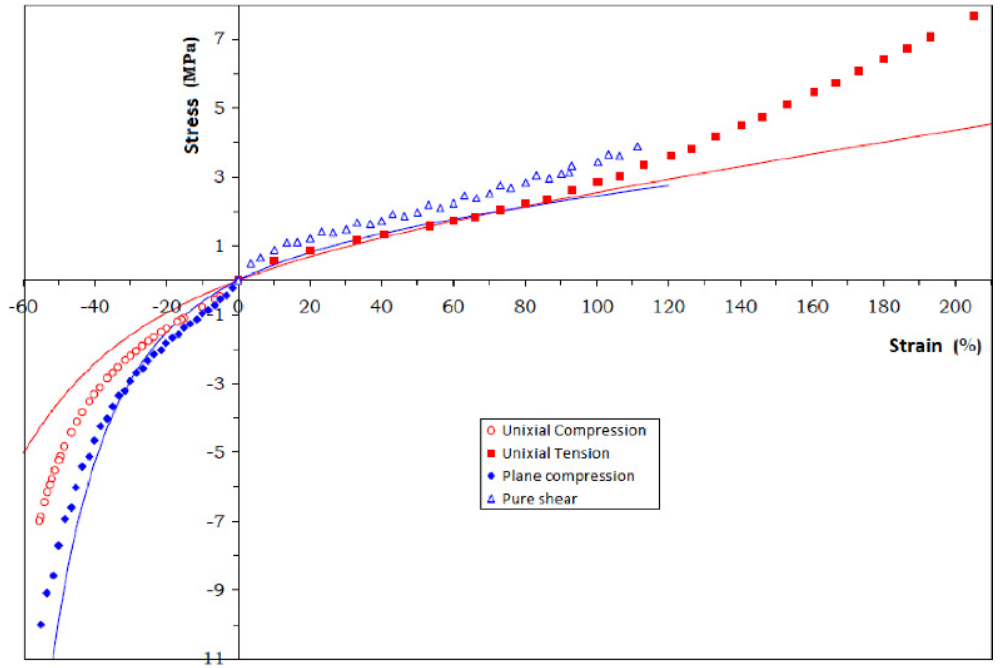

Figure 8. Hyperelastic response of tire rubber.
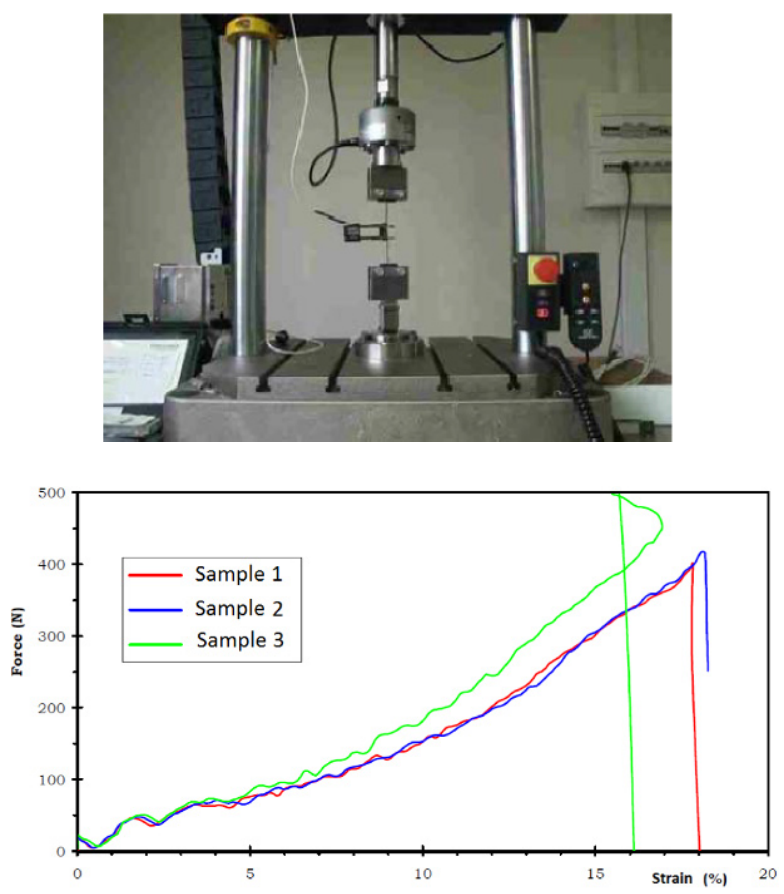

Figure 9. Experimental device and tension test response of a Carcass ply.

Three specimens of each rubber component were selected and stretched, and data of rubber elongation value for every individual rubber component was obtained by averaging the values from the tests on three specimens of each component, while simple tension tests were carried out on reinforced cords (polyester, nylon, Kevlar). Figure 9 shows a reinforced cord specimen tested in these experiments.

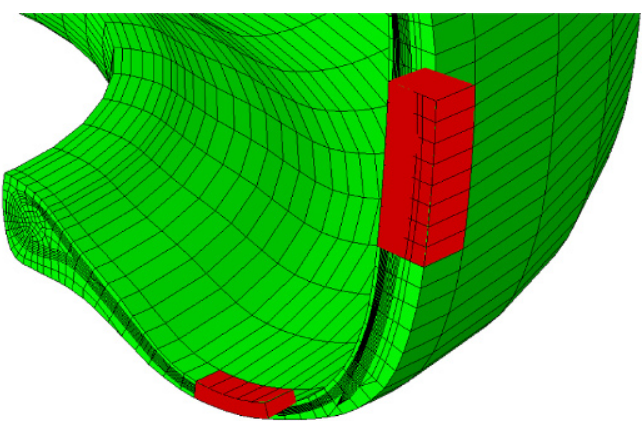

${ }_{x}^{2}$

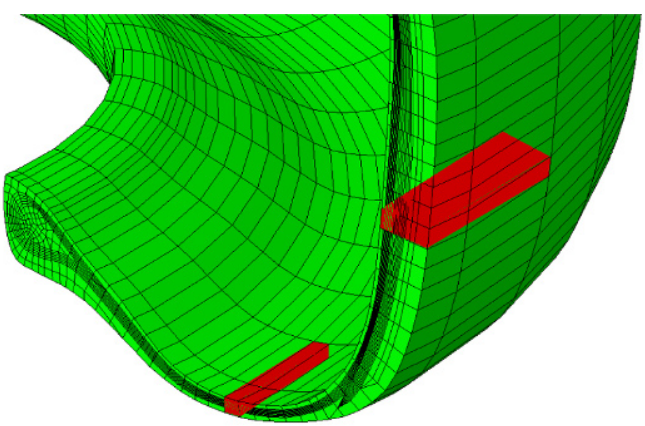

$\mathrm{z}_{\mathrm{x}}^{\mathrm{y}}$

Figure 10. Radial and circumferential cutting directions.

The geometric complexity of tires makes it difficult to cut specimens for classical tests. Specimens were therefore cut only in the radial and circumferential direction, but not in that of the thickness (see Figure 10). 


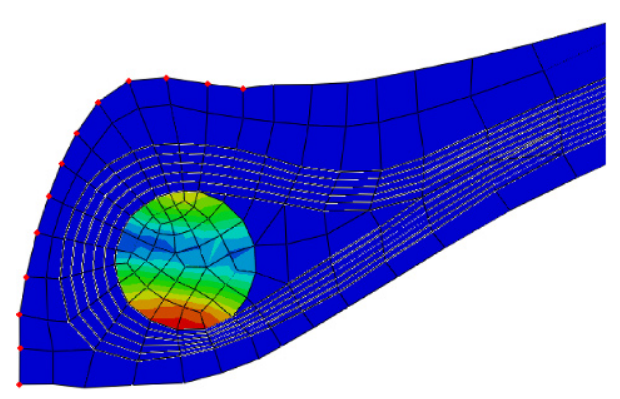

Figure 11. Tire nodes adhering to the reference rim point.

\subsection{Interactions}

\subsubsection{Tire/rim contact}

As said in section 3.2, the contact between the tire and the rim was simplified by assuming that the tire adheres to the rim as indicated by the highlighted nodes on the left-hand side and the upper left corner (see Figure 11) [16].

\subsubsection{Coulomb friction at tire/ground contact zone}

The tire/ground contact complicates the finite element model since contact and friction problems are highly nonlinear. These effects cannot be overlooked, however. The contact problem is modeled in a soft contact manner using exponential pressure-overclosure regularization, where the clearance $c_{0}$ and the contact pressure at zero clearance $\lambda_{0}$ are defined based on a numerical sensitivity study. The Coulomb friction is modeled using a stiffness method $[4,5]$. The stiffness method used for friction in Abaqus/Standard is a penalty method that permits some relative motion of the surfaces [37], the magnitude of this sliding is limited to the elastic slip. The initial value of the elastic slip is calculated as a small fraction of the "characteristic contact surface length".

\section{6. $\quad$ Tire modeling steps}

In the present study, finite element analyses were performed in four consecutive stages. In the first stage, the tire was modeled under an inflation pressure using 2-D axisymetric model. A 3-D model was then developed by revolving the $2-D$ one. Either the dynamic analysis with acceleration or the steady state analysis was then carried out in the third stage to obtain the tire's free rolling conditions. In the last stage, a slip angle was chosen to simulate the tire under cornering conditions. A thermomechanical analysis was performed to account for the thermal effects due to contact with friction. This stage was performed after the 3-D static analysis.

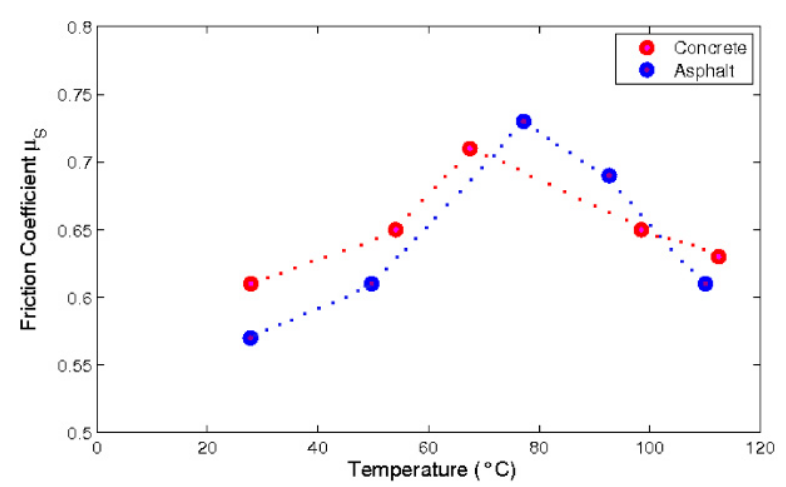

Figure 12. Friction coefficient $\mu_{s}$ depending on the temperature and type of runway.

\subsection{Loadings}

The loading is characterized by the following sequences:

- The tire was inflated at a rated pressure $p_{0}$ and charged at the normal force $F_{Z}$. The cornering was obtained by splitting the rolling velocity into longitudinal and lateral components, $V_{X}$ and $V_{Y}$ respectively [29]. The $X-Y$ plane is the runway plane with $X$ the strait rolling direction and $Z$ is the normal vertical loading direction.

- The heat generated in the contact area at a given slip angle is used in the thermal analysis step. The non-uniform computed thermal flux is applied to a surface corresponding to the contact area and rotated around the tread to simulate the rolling of a tire.

\section{Friction coefficient measurement}

During the rolling tests, we observed that some smoke were generated under specific tire loading conditions, and traces of rubber were deposited on the ground, because of the increase in the temperature due to friction and the rubber wear due to chemical transformations occurring on the rubber surface. This phenomenon can imply a lubrication of the contact by generating the third body between tire and ground. The increasing of temperature on the tread surface $[4,34]$ can modify sensitively the friction coefficient. The evolution of the friction coefficient with temperature determined in some laboratory tests on tire tread specimens is shown in Figure 12 for two different runway surfaces (concrete and asphalt).

The results giving the evolution of the friction coefficient with the temperature are in line with Chichinadze's findings [35]. The friction coefficient reached a maximum value of 


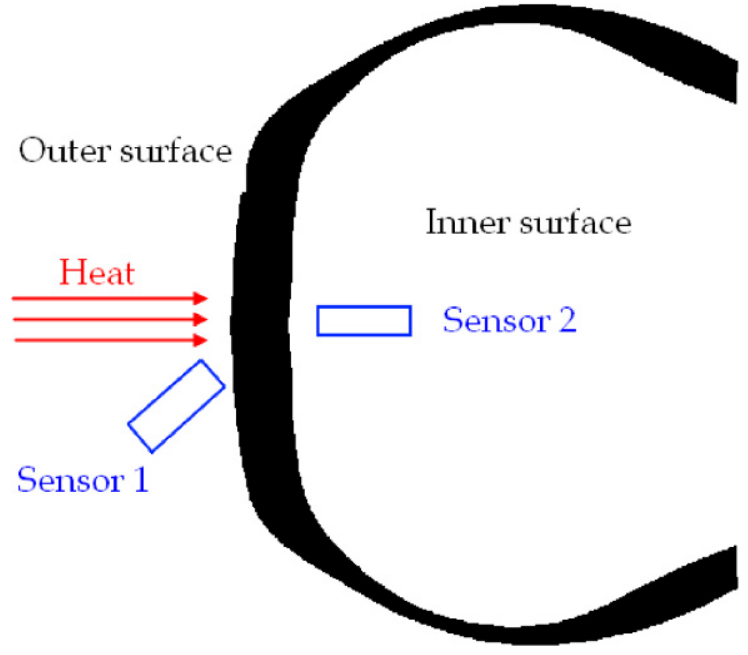

Figure 13. Diagram of the experimental test.

0.74 at a temperature of around $80{ }^{\circ} \mathrm{C}$. These data will be used as input for the friction coefficient estimation as a function of the local temperature. Thus, for a given temperature distribution in the contact area will correspond a friction coefficient distribution according to the above curve.

\section{Temperature distribution in the tire thickness}

The aim of this section is to define how the temperature spreads through tire from the tread side to the inner side. The experimental test shown in Figure 13 consisted in warming the tire tread on one side, using a thermal paint burner $\left(150{ }^{\circ} \mathrm{C}\right)$ and measuring simultaneously the temperature on both the outer surface (Sensor 1) and the inner surface (Sensor 2). The sensors used were two infrared thermometers. The experiment was repeated several times, for different warming periods.

Figure 14 shows the evolution of the temperature on the tire tread and inflating surfaces. Despite the increasingly long warming time, the inner surface temperature remained almost constant. On the outer surface, it can be observed that during the first five minutes, the temperature increased and then remained constant.

The internal temperature gradient observed was small. When the temperature increased to $100{ }^{\circ} \mathrm{C}$ on the tire tread, it increased on the inflating surface by only $10^{\circ} \mathrm{C}$. The maximum internal temperature rise was about $17^{\circ} \mathrm{C}$ and it was obtained after 20 minutes of heating time and an external temperature of $120^{\circ} \mathrm{C}$.

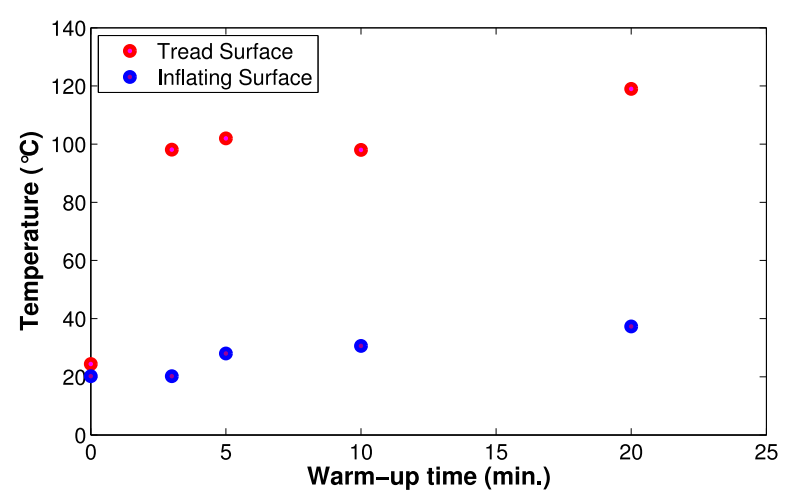

Figure 14. Increase in the temperature of tire tread and inflating tire surfaces.

\section{Thermomechanical approach: steady state thermal analysis}

The conventional approach to thermomechanical automobile tire problems consists in Lagrangian methods, where mesh used to discretize the tire rotates relative to the ground. Since many revolutions are required to reach a stabilized rolling, this approach is prohibitively expensive and cumbersome [36]. In the present approach, a new sequential thermomechanical coupling procedure is performed using the Eulerian/Lagrangian approach for the steady state mechanical analysis, followed by a transient thermal analysis, solving the equations presented in Section 2.

We recall that the material properties are assumed to be independent of the temperature and the only heat source is assumed to be the friction. In the numerical applications presented in the following, only moderate speeds are treated, thus the dissipation due to viscoelasticity will be neglected.

\subsection{Synopsis}

The main goal of this approach is to predict the thermomechanical behavior of the tire from $0^{\circ}$ up to a prescribed skid angle $\beta_{\text {pres. }}$. The Thermal Steady State algorithm presented in this section (see Figure 15) is a two-step weak coupling algorithm doing mechanical and thermal calculations. This two-step calculation is performed in an incremental manner, for each $\beta_{i}$ from $0^{\circ}$ to $\beta_{\text {pres }}$.

- The mechanical procedure computes the deformed configuration of the tire for a given temperature distribution and a new temperature distribution corresponding to the new contact area.

- The thermal procedure uses the temperature distribution from the previous step as a heating source 


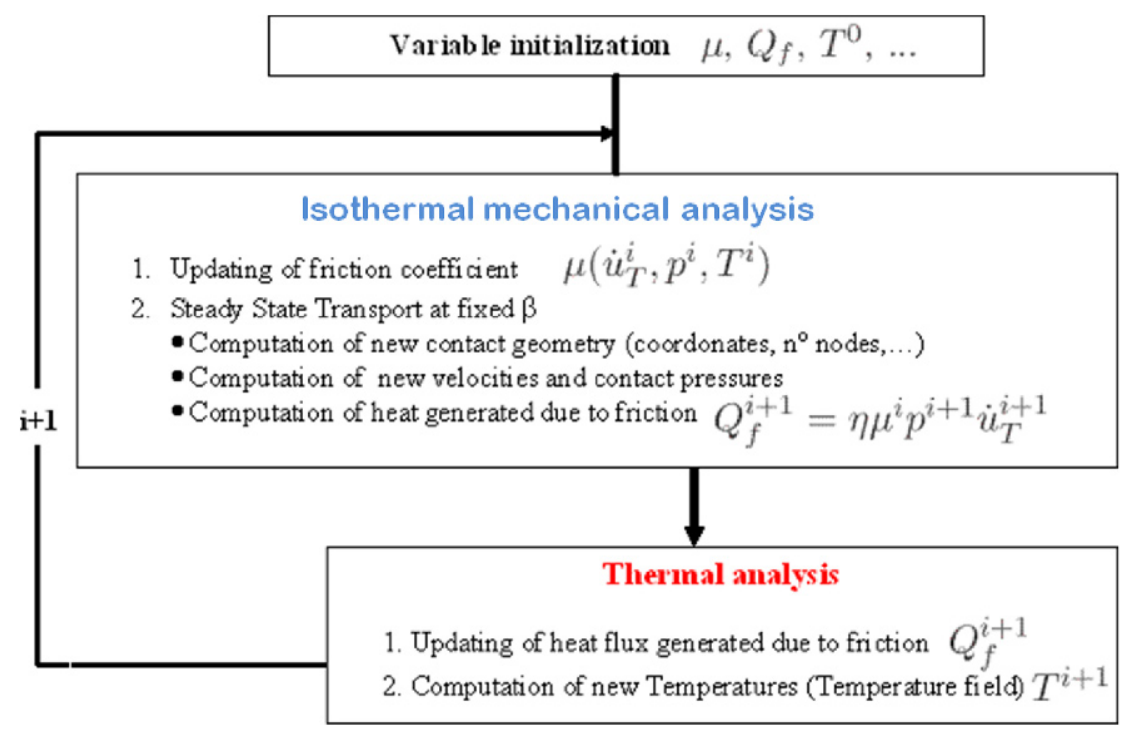

Figure 15. Steady State Thermal algorithm.

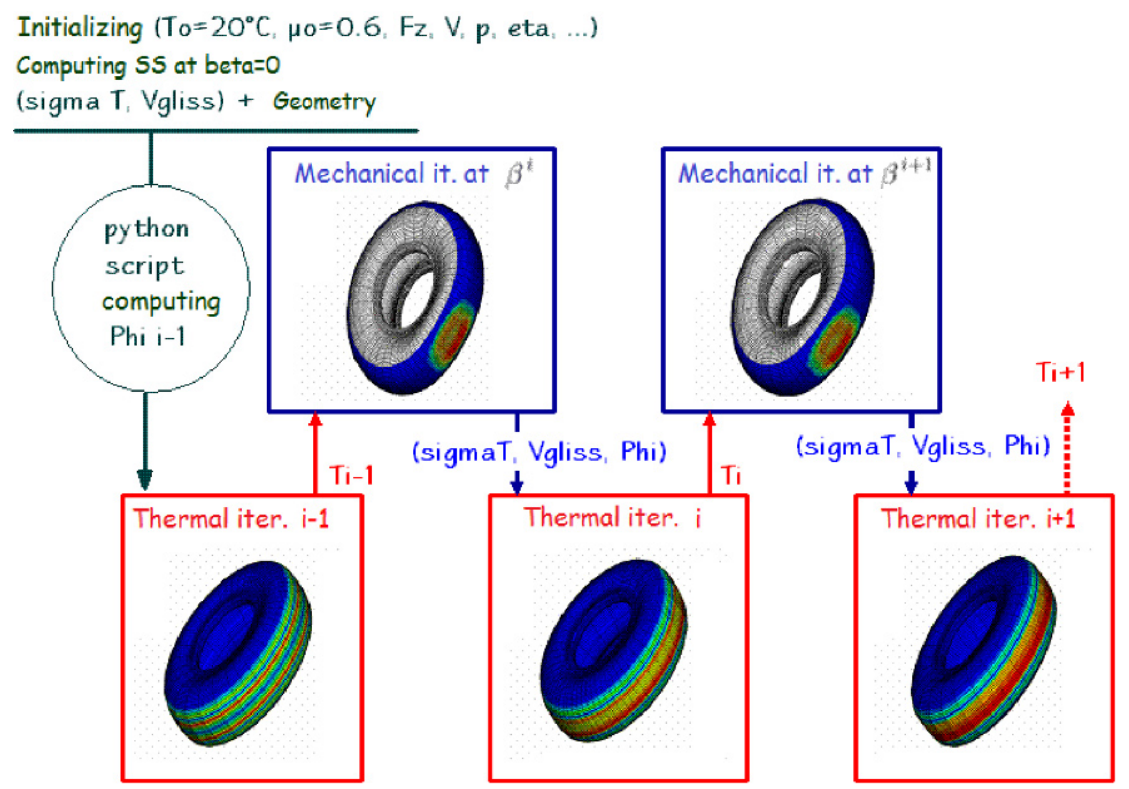

Figure 16. Thermomechanical coupling process on an aircraft tire without any grooves.

turning around the tire tread in order to simulate the heating due to friction in the contact area. The number of turns of the heating source corresponds to the number of rolling turns of the real tire needed to reach a stabilized temperature distribution.

Using a temperature dependent friction coefficient, the thermomechanical coupling is obtained by updating the local friction coefficients $\mu_{\text {local }}$ in the contact area.

\subsection{Process}

We begin by addressing the mechanical problem where $\beta_{0}=0^{\circ}$ with the initial temperature boundary conditions $\left(T_{0}\right)$, rolling velocity conditions $(v)$, vertical loading conditions referred to the aircraft weight $\left(F_{Z}\right)$, internal inflating pressure $\left(p_{0}\right)$, initial friction coefficient $\left(\mu_{0}\right)$ and some other parameters such as the heat share coefficient, thermal convection coefficient, thermal conductivity, specific heat, etc. 
The process (Figure 16) follows these steps:

1. Mechanical iteration $i-1$ : this is a mechanical analysis in which a steady state rolling approach is used, where the cornering condition $\beta_{i-1} \neq 0^{\circ}$ is used to define the sliding velocities, the contact pressures at each node and the contact geometry (coordinates and number of contact nodes). Data are obtained via a python script and processed. The results obtained are used as initial conditions in the thermal step $i-1$. The temperature distribution in the contact area resulting from the friction can thus be computed.

2. Thermal iteration $i-1$, this is a convection/diffusion thermal analysis. In this analysis, the mesh configuration corresponds to the final configuration in the $i-1$ mechanical step. The temperature distribution in the contact area at the end of the Mechanical iteration $i-1$ will be considered as a heat flux $Q_{f}$ rotating around the tire tread. The new temperature map will be used to define the initial temperature conditions in the next mechanical step $i$.

3. Mechanical iteration $i$ : In this step, the local friction coefficients are first updated and the skid angle $\beta_{i}=\beta_{i-1}+\Delta \beta$ is then incremented. A new Steady State computation is performed and the new contact zone geometry and configuration are recorded. $Q_{f}$ is calculated, and this gives the thermal conditions for the thermal step $i$.

4. Mechanical and thermal iterations will be performed at increasing skid angles until the final value of the skid angle $\beta_{\text {pres }}$ is reached.

\section{Results and discussion}

This paper focuses on the application of this FEM aircraft tire model to predict the lateral friction coefficient $\mu_{Y}$ and the self-aligning torque $M_{Z}$, based on taking the frictional thermal effects into account.

The studied tire was about $700 \mathrm{~mm}$ in radius and it was subjected to 15 bars of internal pressure and $250 \mathrm{kN}$ of normal loading. The simulated speeds were $50 \mathrm{~km} / \mathrm{h}$ and $100 \mathrm{~km} / \mathrm{h}$ and the skidding angle was $16^{\circ}$.

The simulations were performed using ABAQUS software for the deformation and the thermal steps, while the dissipation step was performed using an external software program.
Table 1. Material parameters of rubber

\begin{tabular}{lcc}
\hline \multirow{2}{*}{ Tire component } & \multicolumn{2}{c}{ Mooney-Rivlin Constant } \\
\cline { 2 - 3 } & $C_{10}(\mathrm{MPa})$ & $C_{01}(\mathrm{MPa})$ \\
\hline \hline Tread & 0.643 & 0.824 \\
\hline Rubber & 0.658 & 0.032 \\
\hline
\end{tabular}

Table 2. Material parameters of cord layers

\begin{tabular}{lccc}
\hline Cord material & $\mathrm{E}(\mathrm{GPa})$ & Poisson ratio & Orientation $^{a}$ \\
\hline \hline Carcass & 1.90 & 0.3 & $\pm 5.5^{\circ}$ \\
\hline Belt & 14.25 & 0.3 & $90^{\circ}$ \\
\hline Protector Ply & 14.50 & 0.3 & - \\
\hline Belt suppl. & 1.33 & 0.3 & $\pm 11.5^{\circ}$ \\
\hline Steel & 200 & 0.3 & - \\
\hline
\end{tabular}

${ }^{a}$ with respect to the radial direction

\subsection{Material parameters and model size}

The parameters of the rubber were obtained in tests, and are given in Tables 1 and 2 .

The numerical values of thermal properties of the materials used in the finite element model were based on [38] and are presented in Tables 3 and 4.

All calculations were performed on a HP server with two Xeon $3 \mathrm{GHz}$ quad-core processors, using the parallel code version. The model has about 300,000 degrees of freedom.

\subsection{Results}

We first performed a fully coupled thermomechanical analysis in order to show how expensive the original full method can be in comparison with the semi-coupled method presented here. However, in the present analysis, the Classical rolling $(\mathrm{CR})$ method used requires some explanations. We will begin by presenting this CR-method before performing fully- and semi-coupled thermomechanical analyses.

\subsubsection{Classical Rolling}

This fully-coupled method is based on a Lagrangian formulation. Thus, from an observer's point of view, the tire mesh is rotating and moving forward. This simulation requires an acceleration step from zero to a given velocity and a rolling cornering step at a constant given velocity.

Table 3. Thermal properties of the material

\begin{tabular}{lccc}
\hline & $\begin{array}{c}\text { Specific heat } \\
\left(c_{p}\right)\left(\mathrm{J} / \mathrm{kg}^{\circ} \mathrm{C}\right)\end{array}$ & $\begin{array}{c}\text { Thermal conductivity } \\
(\mathrm{k})\left(\mathrm{W} / \mathrm{m}^{\circ} \mathrm{C}\right)\end{array}$ & $\begin{array}{c}\text { Density } \\
(\rho)\left(\mathrm{kg} / \mathrm{m}^{3}\right)\end{array}$ \\
\hline \hline Rubber & 0.2 & 1900 & 1125 \\
\hline Steel & 53.7 & 465 & 7900 \\
\hline
\end{tabular}


Table 4. Thermal convection coefficients

\begin{tabular}{|c|c|c|c|}
\hline & \multicolumn{3}{|c|}{ Thermal convection coefficients $\alpha\left(\mathrm{W} / \mathrm{m}^{2}{ }^{\circ} \mathrm{C}\right)$} \\
\hline Speed (km/h) & Inner $\left(S_{1}\right)$ & Sidewall $\left(S_{2}\right)$ & $\operatorname{Rim}\left(S_{3}\right)$ \\
\hline 60 & 7.50 & 40.0 & 3.00 \\
\hline 80 & 7.50 & 52.5 & 3.00 \\
\hline 100 & 7.50 & 65.0 & 3.00 \\
\hline 120 & 7.50 & 82.5 & 3.00 \\
\hline
\end{tabular}
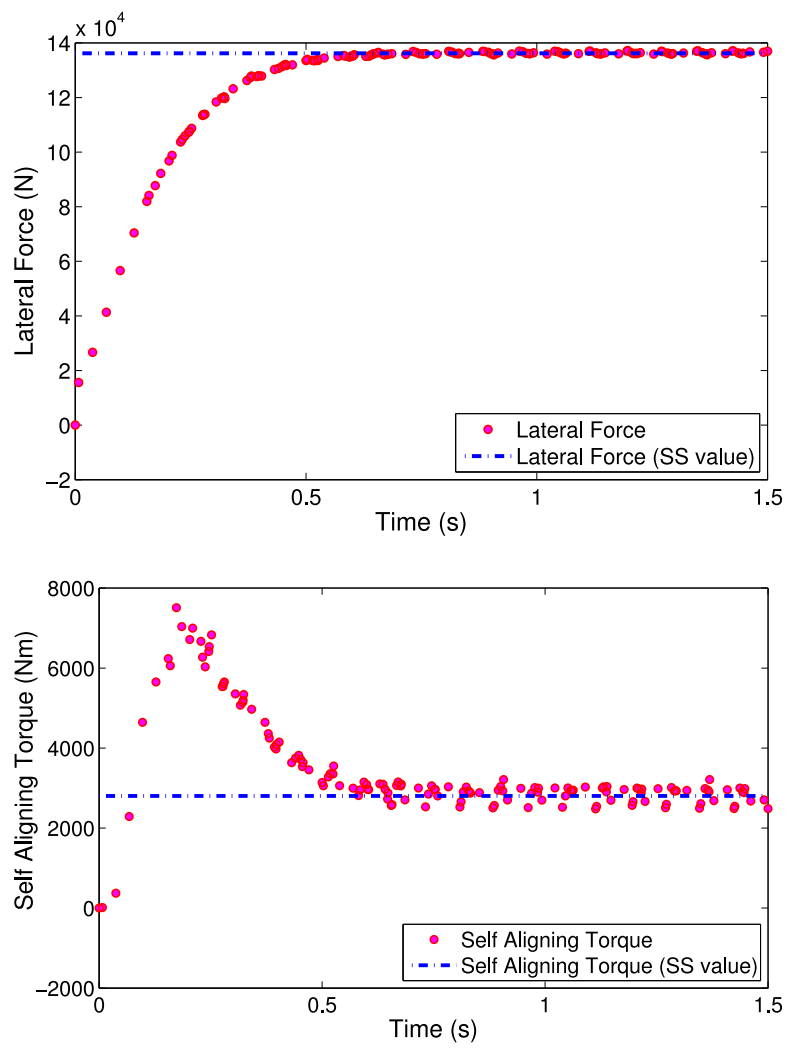

Figure 17. Lateral Force and Self Aligning Torque in RC.

This method is far too time consuming and expensive for industrial applications. We have discussed the advantages and disadvantages of this method in [4]. In terms of the CPU time with 4 processors, 72 hours are required to compute one couple $\left(\mu_{Y}, M_{Z}\right)$ at each slip angle $\beta_{i}$.

When the classical rolling method is used, only one point is obtained for the chosen loading parameters. As Figure 17 shows, the tire response is time-dependent with this method. It also can be noted that several tire rotations are required to reach the stationary phase at which $M_{Z}$ and $\mu_{Y}$ are evaluated. However, many simulations and much time are required to obtain all the slip angles, while only one simulation is needed in the case of the steady state method.

\subsubsection{Fully coupled thermomechanical analysis}

The thermal parameters are assumed to be constant along the whole boundary. In addition, the heat flux resulting from mechanical deformation is neglected. In order to test the ability of the fully coupled thermomechanical method to determine some software parameters and to estimate the efficiency of the tool, we began by simulating a pure sliding movement in which the tire is pulled along the ground before performing a cornering rolling movement in which the tire is rolling at a given velocity and a given slip angle.

1. Pure sliding The pure sliding is obtained by pulling the tire. Only one loading case is simulated. The tire is pulled 4 meters along the ground at a constant speed of $50 \mathrm{~km} / \mathrm{h}$. In this case, we observe that the temperature increases significantly when the tire slides lengthways, even over a short distance. The rubber reaches a surface temperature of $190{ }^{\circ} \mathrm{C}$ (Figure 18), which is close to the critical temperature at which the rubber is deposited on the concrete road [34].

2. Cornering rolling Cornering rolling is obtained by imposing longitudinal and lateral velocities. The velocities considered are $v=50 \mathrm{~km} / \mathrm{h}$ and $v=$ $100 \mathrm{~km} / \mathrm{h}$, both at $\beta=16^{\circ}$. The Figure 19 shows the temperature distribution of the tire rolling at $v=50 \mathrm{~km} / \mathrm{h}$. In every instance, the increase in the temperature occurs on tire tread surface, and temperature decreases into the thickness. In Figure 19, it can be seen that the warming occurs on the leading edge of the sliding tire and that the reinforced zone seems to be a thermal barrier.

Figure 20 shows the evolution of the temperature at a tire tread node at the two velocities under investigation. In order to better understand the friction heating process, we have neglected the convection effects for these simulations. The temperature evolution follows a step wise curve: the slope characterizes the increasing of the node temperature in the contact patch due to frictional heating and the plateau corresponds to the node constant temperature when it is out of the contact patch. The node is located on the center of the tread in the tire cross section.

\subsubsection{Sequentially coupled thermomechanical analy- sis}

In this section, thermal-mechanical analysis is performed on a tire using the sequential method presented in section 6. In this case, the heat flux is calculated from the mechanical response and injected into the thermal model. 

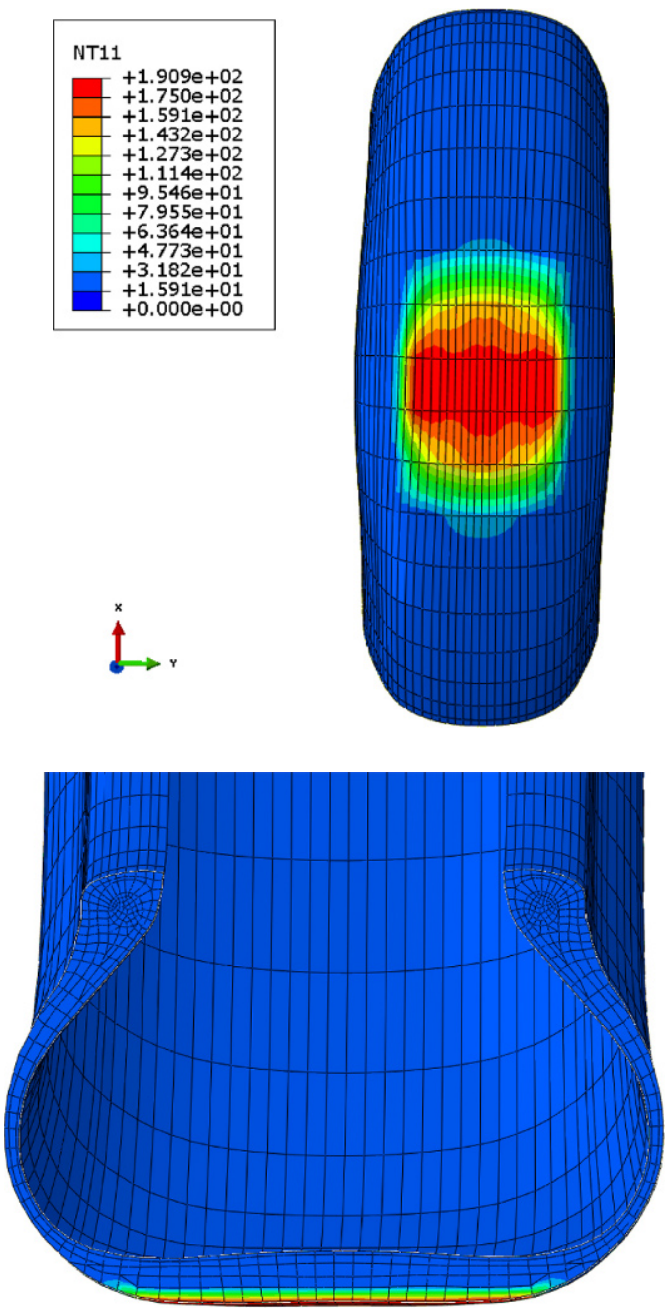

Figure 18. Temperature gradient in a pure sliding simulation at $50 \mathrm{~km} / \mathrm{h}$.

The resulting temperatures are then applied to a new mechanical analysis.

In order to show the influence of the temperature on the lateral friction coefficient $\mu_{Y}$ and on the self-aligning torque $M_{Z}$, a purely mechanical analysis was performed under the same loading conditions and skid angle.

All the simulations were done with constant $\mu_{0}=0.6$ and variable $\mu=\mu(T)$ corresponding to the concrete surface in Figure 12. The tire was submitted to an inflating pressure $p_{o}=15$ bars, a normal loading force $F_{Z}=250 \mathrm{kN}$, a travel velocity $v=50 \mathrm{~km} / \mathrm{h}$ and a skid angle $\beta_{\text {pres }}=16^{\circ}$. As was to be expected, in the case of the mechanical simulation without any temperature dependance, the lateral friction coefficient $\mu_{Y}$ reaches the plateau of $\mu_{0}$ with respect to the Coulomb's friction law. $\beta_{\max }$, the angle for which the self-aligning torque is maximum, seems to be in good agreement with experimental results. The self-aligning
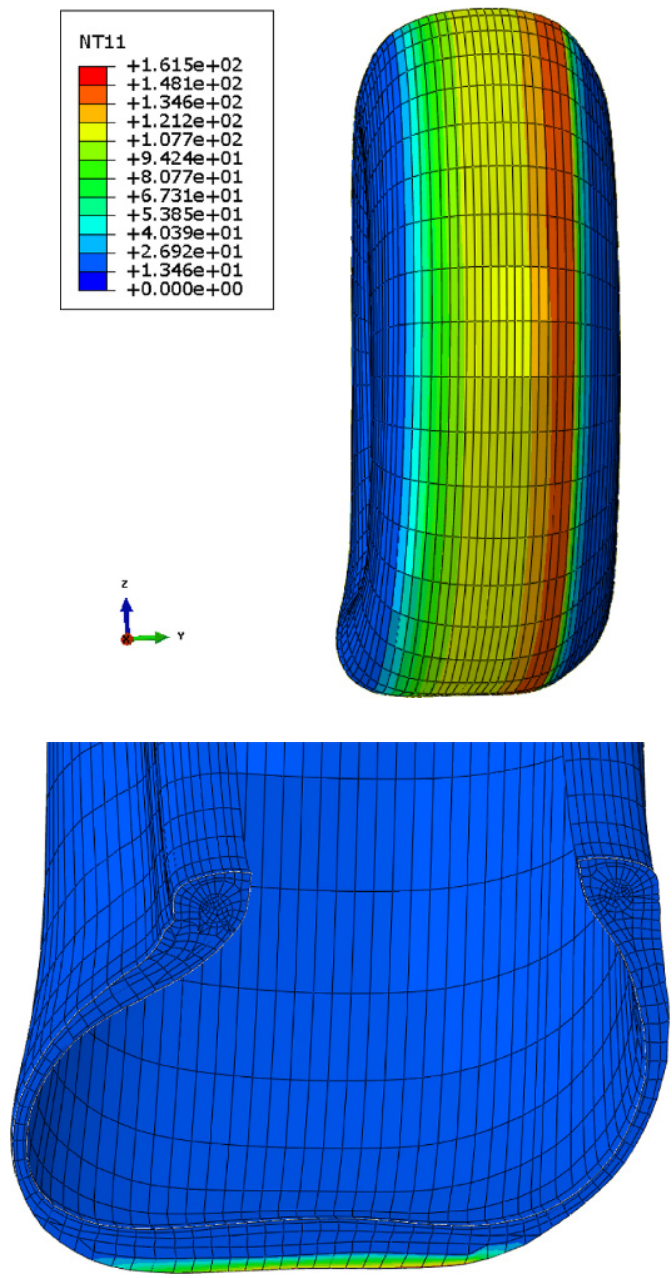

Figure 19. Temperature gradient in a cornering simulation at $v=$ $100 \mathrm{~km} / \mathrm{h}$ and $\beta=16^{\circ}$.

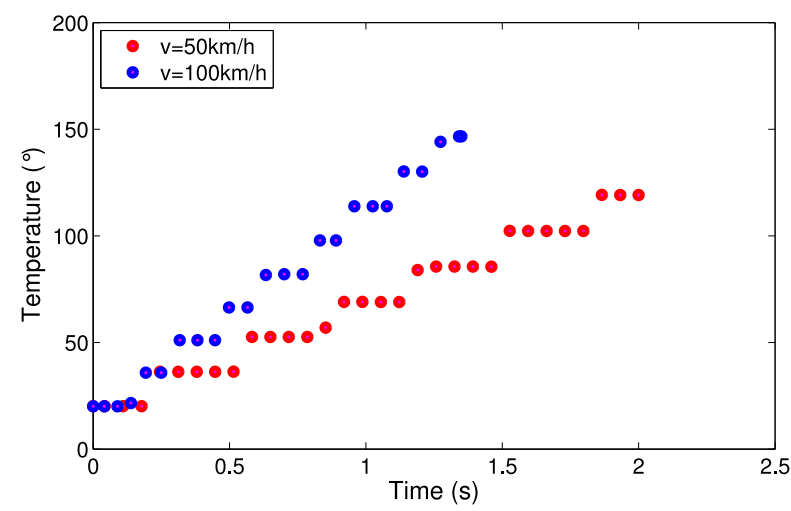

Figure 20. Temperature increase at a tire tread node at velocities of $v=50 \mathrm{~km} / \mathrm{h}$ and $100 \mathrm{~km} / \mathrm{h}$ and $\beta=16^{\circ}$. 

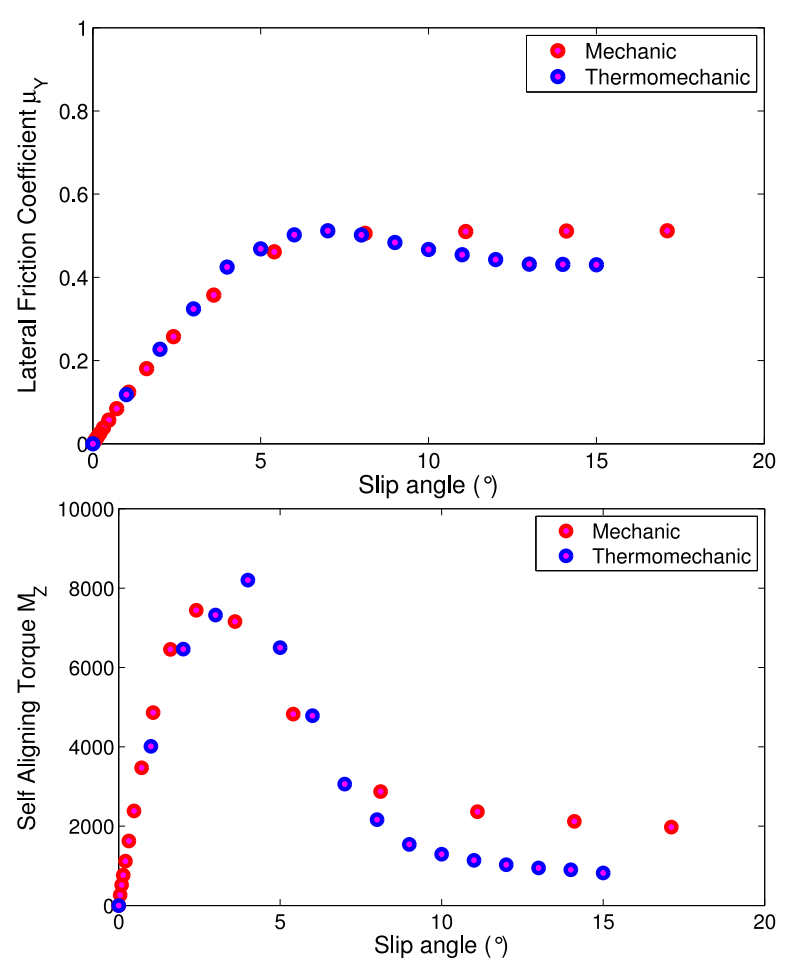

Figure 21. Comparison between the mechanical and the thermomechanical results obtained with constant $\mu_{0}=0.6$ and variable $\mu=\mu(T)$ under given loading conditions $\left(p_{o}=\right.$ 15 bars, $F_{Z}=250 \mathrm{kN}, v=50 \mathrm{~km} / \mathrm{h}, \beta=16^{\circ}$ ).

torque $M_{Z}$ increases up to $\beta_{\max }$ but decreases without tending towards zero.

In the case of the thermomechanical semi-coupled approach, the dependence of the friction coefficient on the temperature resulted in a decrease in $\mu_{Y}$ beyond the $\beta_{\max }$ value, and the self-aligning torque $M_{Z}$ quickly dropped towards null values.

The thermomechanical simulations required 8 hours of $\mathrm{CPU}$ time to obtain a whole curve. These results are shown in Figure 21.

\section{Conclusion}

The present study is the first step in the development of a numerical thermomechanical coupled model for aircraft tires. The aim is to develop a cost-effective alternative thermomechanical approach based on frictional law which takes the thermal effects into consideration, and experimentally defined. By including this law, it is possible to observe the decrease in the lateral friction coefficient $\mu_{Y}$ beyond $\beta_{\max }$, at which the full grip potential is reached and the fast decrease in the self aligning torque $M_{Z}$. Although, the results obtained here are promising, they need to be improved in order to obtain a better quantitative match with the experimental data, and eventually develop a numerical tool for accurately predicting aircraft tire cornering behavior and also at landing and take-off. This will be achieved by improving the process, using accurate thermal data on aircraft tires and assessing the local friction coefficient more accurately.

\section{Acknowledgments}

The authors acknowledge the LRCCP Laboratory. We also acknowledge the contribution of Patrick Heuillet and Lucie Seguin, who contributed importantly to this study by providing experimental data.

\section{References}

[1] Société de technologie Michelin, Le pneu L'adhérence, Michelin France, 2001 (in French)

[2] Pacejka H., Tyre and Vehicle Dynamics, ButterworthHeinemann, Second edition, 2006

[3] Rill G., Vehicle Dynamics, Lecture notes, Hochschule Regensburg, 2006

[4] Kongo Kondé A., Rosu I., Lebon F., Brardo O., Devésa $B$., Etude du comportement en roulement d'un pneu d'avion, Colloque National de Calcul de Structures, Giens 2009, 1, 699-704 (in French)

[5] Kongo Kondé A., Modélisation du roulement d'un pneumatique d'avion, PhD Thesis: University of Provence, Marseille, France, 2011. (in French)

[6] Mc Carthy J.L., Tanner J.A., Temperature Distribution in a Aircraft Tire at Low Ground Speed, NASA Technical Paper 2195, 1983

[7] Tanner J.A., Dreher R.C., Strubb S.M., Smith E.G., Tire Tread Temperatures During Antiskid Braking and "cornering" on a Dry Runway, NASA Technical Paper 2009, 1982

[8] McAllen J.M., Cuitino A.M., Sernas V. Numerical Investigation of Deformation Characteristics and Heat Generation in Pneumatic Aircraft Tires, Part I. Mechanical Modelling, Part II. Thermal Modelling, Finite Element in Analysis and Design, 1996, 23, 241-263

[9] Clark S.K., Dogde R.N., Heat generation in Aircraft Tires under Free Rolling Conditions, NASA Contractor Report 3629, 1982

[10] Ebott, T.G., Hohman, R.L., Jeusette, J.-P., et Kerchman, $\mathrm{V}$., Tire temperature and rolling resistance prediction with Finite Element Analysis, Tire Science and Technology, 1999, 27(1), 2-21 
[11] Rao K.V.N, Kumar R.K, Bohara B.C., Mukhopadhyay R., A Finite element Algorithm for the Prediction of Steady-State temperatures of Rolling Tires, Tire Science and Technology, 2006, 34(3), 195-214

[12] Whicker D., Browne A.L., Segelman D.J., Structure and Use of GMR combined Thermomechanical Tire Power Loss Model, SAE Technical Paper, Number 810164, 1981, 695-704

[13] Yavari B., Tworzydlo W.W., Bass J.M., A Thermomechanical Model to Predict the temperature Distribution of steady-state Rolling tire, Tire Science and Technology, 1993, 21(3), 163-178

[14] Yuksel H.T, An Investigation of Thermomechanical Behaviour of Pneumatic Tires by Finite Element Method, PhD Thesis, Karadeniz Technical University, Turkey, 2002

[15] Ersahin M.A, Finite element analysis of cornering characteristics of rotating tires, $\mathrm{PhD}$ Thesis: Graduate School of Natural and Applied Sciences of The Middle East Technical University, 2003

[16] Ghoreish Reza M.H., Finite Element Analysis of SteelBelted Radial Tyre with Tread Pattern under Contact Load, Iranian Polymer Journal, 2006, 15(8), 667-674

[17] Koishi M., Kabe K., Shiratori M., Tire Cornering Simulation Using an Explicit finite Element Analysis Code, Tire Science and Technology, 1997, 26(2), 109-119

[18] Rao K.V.N, Kumar R.K., Bohara B.C., Mouli C.P., Dynamic Analysis Of Tyre Cornering Behavior Using Explicit Finite Element Code, Proceedings of Twenty First Southeastern Conference On Theoretical And Applied Mechanics, Orlando, Florida, USA, 2002, 131140

[19] Rao K.V.N, Kumar R.K., Bohara B.C., Mouli C.P., Transient Finite Element Analysis of Tire Dynamic Behavior, Tire Science and Technology, 2003, 31(2), 104-127

[20] Nackenhorst U., The ALE-formulation of bodies in rolling contact - Theoretical foundations and finite element approach, Computational Methods in Applied Mechanics and Engineering, 2004, 193, 4299-4322

[21] Mokrani H., Bourouga B., Modèle de coefficient de partage du flux généréà une interface de contact electrothermique - Approche miscroscopique en régime permanent, XXIle Journées Internationales de Thermique - Maroc, 2005, 303-306 (in French)

[22] Behroozi M., Olatunbosum O.A., Ding W., Finite element analysis of aircraft tyre - Effect of model complexity on tyre performance characteristic, Journal of Materials and Design, doi:10.1016/j.matdes.2011.05.055

[23] Cescotto S., Fonder G., A finite element approach for large strains of nearly incompressible rubber-like materials, International Journal of Solids and Structures, 1979, 15(8), 589-605
[24] Holzapfel G.A., On Large Strain Viscoelasticity: Continuum formulation and finite element applications to elastomeric structures, International Journal for $\mathrm{Nu}-$ merical Methods in Engineering, 1996, 39, 3903-3926

[25] Boyce M.C., Arruda E.M., Constitutive models of rubber elasticity, Rubber Chemistry and Technology, 2000, 73, 504-523

[26] Ogden R.W., Saccomandi G., Sgura I., Fitting hyperelastic models to experimental data, Computational Mechanics, 2004, 34, 484-502

[27] Rivlin R.S. Saunders D.W., Large elastic deformations of isotropic materials VII. Experiments on the deformation of rubber, Philosophical Transactions of the Royal Society of London - Series A, 1951, 2243(865), 251-288

[28] Killian H.G., Equation of state of real networks, Polymer, 1981, 22, 209-217

[29] Korunovic N., Trajanovic M., Stojkovic M., Finite Element Model for Steady State Rolling Tire Analysis, Journal of the Serbian Society for Computational Mechanics, 2007, 1 (1), 63-79

[30] Navarro J.P., Contribution à la Modélisation du Pneumatique de l'Avion, PhD Thesis: University of Toulouse III - Paul Sabatier, Toulouse, France, 2003 (in French)

[31] Olatunbosum O.A., Bolarinwa E.O., Finite element simulation of the tyre burst test, Proceedings of the Institution of Mechanical Engineers, 2006, 218, 12511258

[32] Yanjin G., Guoqun Z., Gang C., Influence of Belt cord Angle on Radial Tire Under Different Rolling States, Journal of Reinforced Plastics and Composites, 2006, 25(10), 1059-1077

[33] Lahellec N., Mazerolle F., Michel J.C., Second-order estimate of the macroscopic behaviour of periodic hyperelastic composites: theory and experimental validation, Journal of the Mechanics and Physics of Solids, 2004, 52, 27-49

[34] Sakai H., Araki K., Thermal Engineering Analysis of Rubber Vulcanization and Tread Temperatures during Severe Sliding of a Tire, Tire Science and Technology, 1999, 27(1), 22-47

[35] Awrejcewicz J., Pyrýev Yu., Nonsmooth Dynamics of Contacting Thermoelastic Bodies, Advances in Mechanics and Mathematics, 16, Springer, 2009

[36] ABAQUS/Standard., Theory Manual and Example Problems Manual, Release 6.9, 2010

[37] ABAQUS/Standard., Abaqus Analysis User's Manual, Stiffness method for imposing frictional constraints, Release 6.9, 2010

[38] Yuksel H.T, Karadeniz S., A computation model to predict the thermomechanical behavior of automobile tires, Constitutive Models for Rubber III, Busfield et 
Muhr, 2003

[39] Smith N., Understanding Parameters Influencing Tire Modeling, Department of Mechanical Engineering, Colorado State University, 2004 Formula SAE Platform

[40] Clark S., Mechanics of pneumatic tires, U.S. Dept. of Transportation, 1981

[41] ABAQUS/Standard., Abaqus Analysis User's Manual, Defining reinforcement, Release 6.9, 2010

[42] Benson D.J., An efficient, accurate, simple ALE method for nonlinear finite element programs, Computer Methods in Applied Mechanics and Engineering, 1989, 72, 305-350

[43] Ghosh S., Kikuchi N., An Arbitrary LagrangianEulerian FEM for large deformation analysis for elastic-viscoplastic solids, Computer Methods in Applied Mechanics and Engineering, 1991, 86, 127-188
[44] Ponthot, J.P., Belytchko, T., Arbitrary Lagrangian Eulerian Formulation for Element Free Galerkin Method, Computer Methods in Applied Mechanics and Engineering, 1998, 152, 19-46

[45] Liu W.K., Belytchko T., Chang, H., An Arbitrary Lagrangian-Eulerian Finite Element Method for Pathdependent Materials, Computer Methods in Applied Mechanics and Engineering, 1986, 58, 227-245

[46] Yamada T., Kikuchi F., An Arbitrary LagrangianEulerian Finite Element Method for Incompressible Hyperelasticity, Computer Methods in Applied Mechanics and Engineering, 1993, 102, 149-177

[47] Ghoreishy M.H.R. A State of the Art Review of the Finite Element Modelling of Rolling Tyres, Iranian Polymer Journal, 2008, 17(8), 571-597 